\title{
Revisitando a Pesca Artesanal na Embrapa. Um "Oceano azul” de oportunidades ou
}

\section{um "oceano vermelho" de ameaças?}

\author{
Revisiting artisanal fishing at Embrapa. A "blue ocean" of opportunities or a "red ocean" of
} threats?

\author{
Revisando la pesca artesanal en Embrapa. ¿Un "océano azul" de oportunidades o un "océano \\ rojo" de amenazas?
}

\begin{abstract}
Resumo
Objetivou-se com esta revisão, descrever as principais características, os principais gargalos, sinais e tendências que o setor da pesca artesanal apresenta nos diferentes ambientes onde ocorre no Brasil, seja marinho ou continental. Apontam-se também as possíveis direções estratégicas da Empresa Brasileira de Pesquisa Agropecuária-Embrapa, no sentido de contribuir para dar mais visibilidade à esta cadeia produtiva e integrar pesquisa, desenvolvimento e inovação. Estratégias inovadoras como o enfoque ecossistêmico, mesmo ainda tímidas no Brasil, surgem como possibilidade de navegar em "Oceanos azuis" em que, a busca de mercados não explorados se traduz em fomentar estratégias para conciliar capturas sustentáveis, conservação, respeito à dinâmica socioeconômica e o fortalecimento da Governança através da participação dos pescadores nas tomadas de decisão. É traçado ainda um panorama mundial e brasileiro do setor, assim como a participação da Embrapa neste contexto. Por fim, destacam-se alguns caminhos possíveis de atuação da Embrapa na cadeia produtiva da pesca artesanal como por exemplo a atuação em ambientes marinhos, agregação de expertises internas na Empresa, utilização de modelos HUB de atuação e o fomento de pesquisas com Enfoque ecossistêmico. Independente do caminho a ser seguido, é necessária uma mudança de mentalidade na tratativa com este público-alvo, utilizando abordagens participativas e trabalho em redes colaborativas com parceiros estratégicos. Para navegar no tão almejado "Oceano azul", e deixar para trás o "Oceano vermelho" de incertezas, a visão de futuro necessária para o avanço na fronteira do conhecimento poderá colocar o Brasil em patamares exemplares de gestão pesqueira.
\end{abstract}

Palavras-chave: Pesca artesanal; Marinha; Continental; Atuação estratégica.

\begin{abstract}
The aim of this review was to describe the main characteristics, bottlenecks, signs and trends that the artisanal fishing sector presents in the different environments where it occurs in Brazil, whether marine or continental environments. It also points out the possible strategic directions of Brazilian Agricultural Research Corporation- Embrapa in order to contribute to give more visibility to this production chain and to integrate research, development and innovation. Innovative strategies such as the ecosystem approach, even though they are still timid in Brazil, appear as a possibility of navigating "Blue Oceans" in which, the search for unexplored markets translates into fostering strategies to reconcile sustainable catches, conservation, respect for socioeconomic dynamics and the strengthening governance through the participation of fishermen in decision-making. A global and Brazilian review of the sector is also outlined, as well as Embrapa's participation in this context. Finally, we highlight some possible ways in which Embrapa operates in the artisanal fisheries production chain, such as operating in marine environments, aggregating internal expertise at the Company, using HUB models of action and promoting research with an ecosystemic approach. Regardless of the path to be followed, it is necessary to change the mentality in dealing with this target audience, using participatory approaches and working in collaborative networks with strategic partners. In order to navigate the longed-for "Blue Ocean", and leave behind the "Red Ocean" of uncertainty, the vision of the future necessary for advancing on the frontier of knowledge may place Brazil on exemplary levels of fisheries management.
\end{abstract}

Keywords: Artisanal fishing; Marine; Continental; Strategic goals.

\section{Resumen}

El objetivo de esta revisión fue describir las principales características, los principales cuellos de botella, signos y tendencias que presenta el sector de la pesca artesanal en los diferentes ambientes donde ocurre en Brasil, sea marino 
o continental. También señala las posibles orientaciones estratégicas de Corporación Brasileña de Investigación Agropecuaria-Embrapa para contribuir a dar más visibilidad a esta cadena productiva e integrar la investigación, el desarrollo y la innovación. Estrategias innovadoras como el enfoque ecosistémico, aunque aún tímidas en Brasil, aparecen como una posibilidad de navegar en "Océanos Azules" en los que, la búsqueda de mercados inexplorados se traduce en fomentar estrategias para conciliar capturas sostenibles, conservación, respeto socioeconómico dinámica y el fortalecimiento de la gobernanza mediante la participación de los pescadores en la toma de decisiones. También se perfila un panorama global y brasileño del sector, así como la participación de Embrapa en este contexto. Finalmente, destacamos algunas posibles formas en las que Embrapa opera en la cadena productiva de la pesca artesanal, tales como operar en ambientes marinos, agregar experiencia interna en la Compañía, utilizar modelos de acción HUB y promover la investigación con enfoque ecosistémico. Independientemente del camino a seguir, es necesario cambiar la mentalidad en el trato con este público objetivo, utilizando enfoques participativos y trabajando en redes colaborativas con socios estratégicos. Para navegar el ansiado "Océano Azul" y dejar atrás el "Océano Rojo" de la incertidumbre, la visión de futuro necesaria para avanzar en la frontera del conocimiento puede colocar a Brasil en niveles ejemplares de gestión pesquera.

Keywords: Pesca artesanal; Marino; Continental; Desempeño estratégico.

\section{Introdução}

O termo Pesca Artesanal ou de pequena escala é frequentemente apresentado como uma atividade caracterizada pela baixa produtividade e rendimento (Silva, 2012), que emprega mão de obra familiar e possui baixo grau tecnológico (Gentil et al., 2020). No entanto, esta atividade possui numerosas e complexas especificidades e levam em consideração fatores sociais, políticos, institucionais, econômicos e ambientais intrínsecos a cada local. Seus usuários, os pescadores artesanais, utilizam diversos meios de produção (petrechos, embarcações e estratégias) para capturar diversos recursos geralmente pouco abundantes, em um meio em constante mudança (Diegues, 1983). Nos locais onde ocorre, a pesca artesanal é considerada um indicador de qualidade ambiental, sendo ainda uma importante estratégia de conservação dos recursos pesqueiros quando bem manejada (Catella et al., 2012).

Globalmente, a pesca artesanal possui papel fundamental para a manutenção socioeconômica, ambiental, cultural, e segurança alimentar de 120 milhões de pessoas direta e indiretamente (Chuenpagdee and Jentoft, 2019, Lynch et al, 2016; FAO 2015). Na América Latina e Caribe (LAC), o setor representa cerca de $11 \%$ da produção mundial de pescado oriundo da pesca em pequena artesanal (Pauly \& Zeller, 2016) e 74\% de tudo que vem da pesca nesta região em comparação com a pesca industrial (Salas et al., 2019).

No Brasil, a pesca artesanal ocorre em todos os ambientes aquáticos e biomas do território. Seja marinho, na costa litorânea com mais de $8.500 \mathrm{~km}$ de extensão de Norte (fronteira com a Guiana) a Sul (Fronteira com Uruguai), seja continental, nas Bacias hidrográficas totalmente brasileiras (São Francisco e Tocantins-Araguaia) ou fronteiriças como a Bacia Amazônica e do Paraguai/pantanal. Independente do ambiente onde a pesca ocorre, o Brasil tem à disposição a maior biodiversidade de peixes (ictiofauna) do mundo, tanto de espécies marinhas quanto continentais (Lowe McConnell, 1999). Porém, em termos produtivos não sabemos exatamente o quanto se captura anualmente. Desde 2009, não há coleta de dados sistematizados da pesca artesanal marinha e as estatísticas da FAO se baseiam em extrapolações/imputações de dados e estimativas de médias históricas defasadas de mais de uma década (Zamboni et al., 2020; FAO, 2020). No caso da pesca artesanal continental a estimativa é ainda mais difícil pois não há dados que congreguem todas as bacias de forma unificada. Para algumas bacias, como a Tocantins-Araguaia nunca houve coletas sistemáticas disponibilizadas publicamente, o que impossibilita conhecer o setor e promover o desenvolvimento de políticas públicas mais adequadas. A importância deste setor na região amazônica, por exemplo, é determinante não apenas pela questão cultural e ancestral, mas também pela segurança alimentar. A Amazônia possui a maior taxa de consumo mundial de pescado. Em regiões mais remotas, o peixe muitas vezes se apresenta como única fonte de proteína animal ao longo do ano (Oviedo, 2017) e 70\% da população amazônica preferem o peixe como proteína (Lopes et al., 2016). 
A estimativa da FAO aponta que o Brasil produziu aproximadamente 500 mil toneladas oriundas da pesca marinha em 2018, o que coloca o Brasil na $33^{\circ}$ posição mundial. Já na pesca continental, o Brasil está na posição $13^{\circ}$ dos maiores produtores mundiais, com 220 mil toneladas no mesmo ano (FAO, 2020). Com relação ao contingente de pescadores no Brasil, o último censo realizado, em 2011, indicou cerca de 1 milhão de pescadores artesanais, apontando ainda que $85 \%$ desta população possui o ensino fundamental incompleto (MPA, 2013). Tal cenário educacional impõe à pesquisa um grau a mais de complexidade.

A produção subestimada ao longo dos anos, aliado à falta de conhecimento integrado são os principais desafios da governança para a pesca artesanal. Pois a pesca não ocorre isoladamente, ela existe não apenas nos ambientes aquáticos possíveis, mas em contextos rurais e urbanos, envolvendo homens, mulheres e às vezes crianças em atividades complexas de captura e pós-captura. Essa complexa rede de interação torna difícil projetar uma coleta de dados adequada em comparação com a pesca industrial em grande escala, por exemplo. Consequentemente, tem havido pouco esforço coordenado em nível regional e global para coletar de forma sistemática e rotineira dados sobre a pesca artesanal. Alguns casos de sucesso pontuais vêm ocorrendo no Brasil, mas ainda está longe de ser suficiente para ilustrar a contribuição da pesca artesanal para a segurança alimentar, redução da pobreza e desenvolvimento econômico local e regional. Isso se deve, em parte, à natureza da pesquisa em pesca artesanal, que muitas vezes é localizada/regional e que mesmo que seja amplamente divulgada, o conhecimento permanece fragmentado.

Neste sentido, objetivou-se descrever os principais gargalos, sinais e tendências que a pesca artesanal apresenta nos ambientes marinho e continental, assim como apontar possíveis direções estratégicas da Embrapa que contribuam para dar mais visibilidade à esta cadeia produtiva e integrar pesquisa, desenvolvimento e inovação no Brasil.

\section{Metodologia}

A captação de tendencias e sinais de futuro da pesca artesanal, foi feita de duas formas: (i) inserção de conteúdos extraídos de fontes secundárias, principalmente as demandas prioritárias do PROEPSEQUE-2012 e pela (ii) leitura inédita do futuro do agro nesta cadeia produtiva. Na primeira parte, foram expostas as principais carências do setor assim como as iniciativas de pesquisa existentes e as já consolidadas. Analisou-se as perspectivas futuras em pesquisa e como a Embrapa poderá colaborar com as iniciativas já existentes ou criar novos nichos e grupos que possam atuar em redes colaborativas.

O PROSPESQUE-2012 foi um grande momento balizador e marco histórico, não só para a Embrapa, mas para o setor pesqueiro como um todo. O Seminário Nacional de Prospecção de Demandas da Cadeia Produtiva da Pesca (Prospesque), capitaneado pela Unidade Pesca e Aquicultura, foi realizado em junho de 2012, em Palmas (TO), reunindo dezenas de especialistas nas quatro subáreas do setor pesqueiro brasileiro: pesca artesanal continental, pesca artesanal marinha, pesca esportiva e pesca industrial. O seminário debateu sobre as principais demandas de pesquisa e desenvolvimento tecnológico (P\&D) que o setor enfrenta atualmente. O produto foi um retrato panorâmico da pesca brasileira com suas principais demandas e necessidades de P\&D e com sugestões de propostas de projetos que as respondam (Lima et al., 2012). Neste sentido, a tônica do evento e do documento produzido foi de que as demandas elencadas e priorizadas seriam a curto, médio e longo prazo (horizonte de 30 anos). Considerou-se neste estudo, apenas o recorte da pesca artesanal (marinha e continental), cujas respectivas demandas, em ordem de prioridade refletem diretamente os anseios do setor (Tabela 1). 
Tabela 1. Priorização de demandas do setor pesqueiro artesanal (marinho e continental), eleitas no Prospesque em 2012 (Lima et al., 2012).

\begin{tabular}{|c|c|}
\hline $\begin{array}{c}\text { Grau de } \\
\text { prioridade }\end{array}$ & Demanda \\
\hline 1 & $\begin{array}{l}\text { Carência de monitoramento e da geração contínua de dados estatísticos da pesca como } \\
\text { subsídio para políticas públicas e implementação de um plano nacional de monitoramento } \\
\text { pesqueiro; }\end{array}$ \\
\hline 2 & $\begin{array}{l}\text { Necessidade de estudos sociais, biológicos, econômicos, ambientais e tecnológicos } \\
\text { vinculados à atividade pesqueira; }\end{array}$ \\
\hline 3 & $\begin{array}{l}\text { Necessidade de obter informações regulares sobre a cadeia produtiva para monitoramento e } \\
\text { orientação de políticas públicas; }\end{array}$ \\
\hline 4 & $\begin{array}{l}\text { Necessidade de pesquisar instrumentos tecnológicos adequados ("tecnologia limpa"), } \\
\text { relativos a: captura, processamento, armazenamento, distribuição e comercialização; }\end{array}$ \\
\hline 5 & $\begin{array}{l}\text { Descontinuidade de pesquisa continuada e necessidade de ampliação do conhecimento acerca } \\
\text { da biologia e dinâmica populacional dos recursos pesqueiros e demais espécies afetadas pela } \\
\text { pesca; }\end{array}$ \\
\hline 6 & $\begin{array}{l}\text { Desenvolvimento de abordagens ecossistêmicas para diagnosticar, avaliar e monitorar a } \\
\text { sustentabilidade dos estoques e dos sistemas aquáticos explotados; }\end{array}$ \\
\hline 7 & Necessidade de elaboração dos planos de gestão dos recursos pesqueiros; \\
\hline 8 & Baixo investimento em pesquisa e monitoramento; \\
\hline 9 & $\begin{array}{l}\text { Falta de interlocução entre as diferentes áreas do conhecimento que podem subsidiar o uso } \\
\text { sustentável dos recursos pesqueiros. Escassez de informações confiáveis e de tecnologias } \\
\text { qualificadas, com a devida abrangência biológica, ecológica e socioeconômica; }\end{array}$ \\
\hline 10 & $\begin{array}{l}\text { Falta de estrutura dos órgãos nacionais responsáveis pelo ordenamento pesqueiro, } \\
\text { desarticulação entre as instituições (públicas ou privadas) na condução de projetos de } \\
\text { pesquisa relacionados a recursos pesqueiros. }\end{array}$ \\
\hline
\end{tabular}

Fonte: Autores.

A partir do Prospesque 2012, a Embrapa Pesca e Aquicultura, cuja Pesca foi imputada como missão nacional, passou a direcionar esforços de acordo as demandas supracitadas, porém, com o corpo técnico limitado. Porém, passados quase uma década, a Embrapa decidiu atualizar o recorte Pesca artesanal marinha e continental, revisitando o setor no sentido de verificar se as demandas eleitas em 2012 ainda eram pertinentes. Neste sentido, foi feita uma pesquisa online (google forms) com 74 (setenta e quatro) stakeholders em todo o território brasileiro. A pesquisa foi realizada no primeiro trimestre de 2021 e teve como objetivo revisitar as demandas eleitas como prioridade no PROSPESQUE-2012, relativos à pesca artesanal marinha e continental. A pesquisa indicou à Embrapa se as demandas de 2012 são verificadas atualmente como mudanças na forma de Sinais (indícios de possíveis mudanças), Tendências (mudanças já consolidadas) ou nenhuma das alternativas, ou seja, nenhuma mudança verificada em cada demanda. Foi realizada uma estatística descritiva simples e qualitativa com coleta de dados direta (Pereira et a., 2018), sendo representada em porcentagem (\%), para indicar a proporção de cada indicador (Sinal, Tendência ou Nenhuma delas) de acordo com cada demanda do Prospesque-2012. Importante salientar que a pesquisa online teve o caráter de percepção, ou seja, a compreensão de cada indivíduo sobre o contexto atual da pesca artesanal, suas expectativas, satisfações e insatisfações, julgamentos e condutas a respeito das demandas do Prospesque-2012. 


\section{Resultados e Discussão}

Considerando os principais e recentes conhecimentos acumulados sobre a pesca artesanal no Brasil, a rede Too Big To Ignore-TBTI (www.toobigtoignore.net) é a mais agregadora. Esta rede de pesquisa global que envolve 81 países e 413 membros, é voltada para mobilizar conhecimento e parcerias para a sustentabilidade da pesca artesanal no mundo. Em 2020, a pesquisa brasileira em pesca artesanal registrou 43 projetos. Estes projetos, por sua vez, indicaram 255 problemas associados à pesca artesanal no Brasil, colocando o país em $5^{\circ}$ posição mundial (Figura 1). A maioria dos problemas relatados nos projetos estão nos subtemas ligados à Governança, Sociocultural e Ecológico, sendo estas as demandas mais urgentes. Uma abordagem de pesquisa considerada de vanguarda pela FAO (2015) e considerada a mais apropriada para a gestão pesqueira artesanal é o Enfoque Ecossistêmico.

Figura 1. Estado da arte em pesquisa sobre a pesca artesanal em 2020, por subtema. Os números em cada país indicam a soma de problemas relatados e o segundo número, o de projetos registrados.
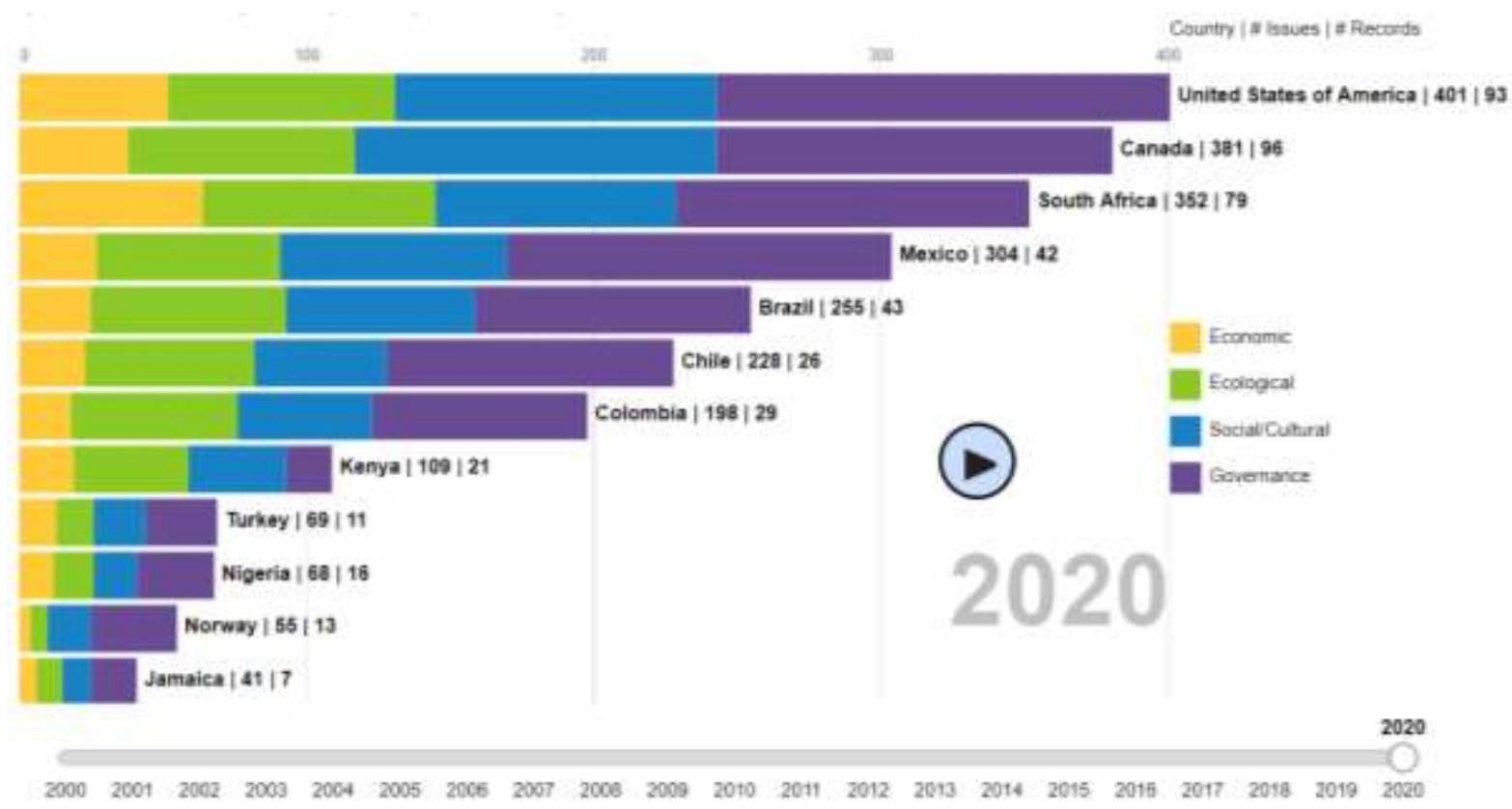

Fonte: https://issfcloud.toobigtoignore.net/.

Esta abordagem se caracteriza na interação do conhecimento biológico dos estoques de peixes (ecologia), com o manejo pelos usuários e seu contexto socioeconômico. Projetos com Enfoque Ecossistêmico para a pesca são recentes na história, mas trazem à tona questões antes pouco consideradas pela pesquisa como a governança, sendo este um fator-chave que determina como o poder e as responsabilidades são exercidos, como as decisões são tomadas e como os cidadãos, no caso os pescadores, podem dar a sua opinião (Graham et al., 2003). Segundo Hilborn (2007) e Cochrane (2005), não há ordenamento pesqueiro eficiente sem considerarmos as relações de governança.

A Governança se torna ainda mais complexa na pesca artesanal, pois envolve: "um sistema no qual a organização social e econômica e as políticas de grupos e organismos interdependentes interagem, sejam eles públicos e privados, e são conectados por doutrinas, ideias e princípios e destinados a servir a um propósito comum, a regulamentação do uso dos recursos pesqueiros" (FAO, 2015). As tomadas de decisão quanto ao manejo pesqueiro devem necessariamente compartilhar objetivos com todas as partes interessadas, utilizando as informações (bioecológicas e socioeconômicas), num ciclo de retroalimentação permanente visando implementar as medidas de ordenamento pesqueiro (FAO, 2015). 
A única proposta encontrada no Brasil, pautada nesta abordagem é o projeto, ainda em execução, "Manejo Sustentável da Fauna Acompanhante na Pesca de Arrasto na América Latina e Caribe - REBYC II-LAC, iniciativa conjunta da FAO e do Fundo Mundial para o Meio Ambiente- FMAM (Global Environment Facility - GEF), que visa a gestão sustentável da pesca e a redução de desperdícios na captura de camarões no litoral brasileiro (BRASIL, 2019). Portanto, as inciativas governamentais futuras, devem considerar esta abordagem em suas estratégias de gestão pesqueira, uma vez que é inovadora quando planejada e executada corretamente. Propostas como a do Enfoque ecossistêmico estão muito alinhadas ao conceito estratégico do "Oceano azul".

O termo "Oceano azul" e "Oceano vermelho" foi criado por Kim e Mauborgne (2005) e ilustra que o oceano vermelho são os mercados atuais em que se encontram a maioria das empresas, buscando a cada momento conquistar os mesmos clientes com produtos parecidos e elevada concorrência gerando assim brigas pelo mercado que mancham o mercado, oceano, assim este mercado altamente competitivo. Já o mercado onde não existe concorrência pois um processo de inovação de valor com a redução dos custos gera um ambiente não concorrencial e desta forma não há conflitos, este mercado, é denominado de oceano azul (Cattaneo et. al, 2017).

Fazendo uma analogia com a pesca artesanal, o oceano vermelho são as atuais limitações e conflitos da pesca com outros setores e principalmente com externalidade às quais os pescadores têm pouco domínio e por isso se tornam frágeis a esses elementos. Exemplo destas externalidades são a degradação generalizada dos ecossistemas costeiros e continentais ocasionados por especulação imobiliária, grandes empreendimentos (petróleo, hidrelétricas, agronegócio), poluição urbana e rural, supressão de vegetação ciliar, falta de assistência técnica e crédito, etc. Já o Oceano azul, seria as estratégias de gestão que considerem a participação popular (Governança) e a pesquisa científica multidisciplinar, com dados sobre os estoques pesqueiros explorados e da socioeconomia local.

Portanto, incentivar estratégias como o Enfoque Ecossistêmico, além de favorecer uma abordagem mais completa, contribui para o alinhamento aos instrumentos internacionais de política pesqueira existentes como: o Código de Conduta Para a Pesca Responsável da FAO (FAO, 1995), A Convenção das Nações Unidas sobre os Direitos do MAR (UNCLOS), as Diretrizes Voluntárias para a Pesca Artesanal (FAO, 2015) e os Objetivos do Desenvolvimento Sustentável (ODS-14), entre outros. Estes instrumentos estabelecem princípios e padrões internacionais de comportamento para práticas responsáveis, com vistas a garantir a efetiva conservação, gestão e desenvolvimento dos recursos aquáticos vivos, com o devido respeito ao ecossistema, à biodiversidade e às relações de governança.

Para ilustrar a complexidade e a carência de conhecimento integrado sobre a pesca artesanal, o Brasil foi considerado o $2^{\circ}$ no ranking mundial (Figura 2) em números de casos de injustiça praticados contra a pesca artesanal, segundo o painel do Sistema de Informações da Pesca artesanal, também coordenado pela rede TBTI. Os tipos de injustiças também estão atrelados a questões sociais, econômica e ambientais. Ainda segundo esta instituição: "A organização comunitária é vital para os pescadores brasileiros de pequena escala. Esses esforços dinâmicos e coletivos ajudam aqueles que lutam para sobreviver às adversidades e, ao mesmo tempo, expõem ao público as condições precárias em que vivem os pescadores artesanais e a falta de ação do governo em relação a essa parte marginalizada da sociedade. Há uma necessidade urgente de políticas públicas que beneficiem os pescadores de pequena escala no Brasil. Afinal, eles são parte essencial da sociedade brasileira e merecem equidade e justiça (Brito \& Eyng, 2020)”. 
Figura 2. Diferentes tipos de injustiça contra a pesca artesanal em estudos de caso de diversos países.

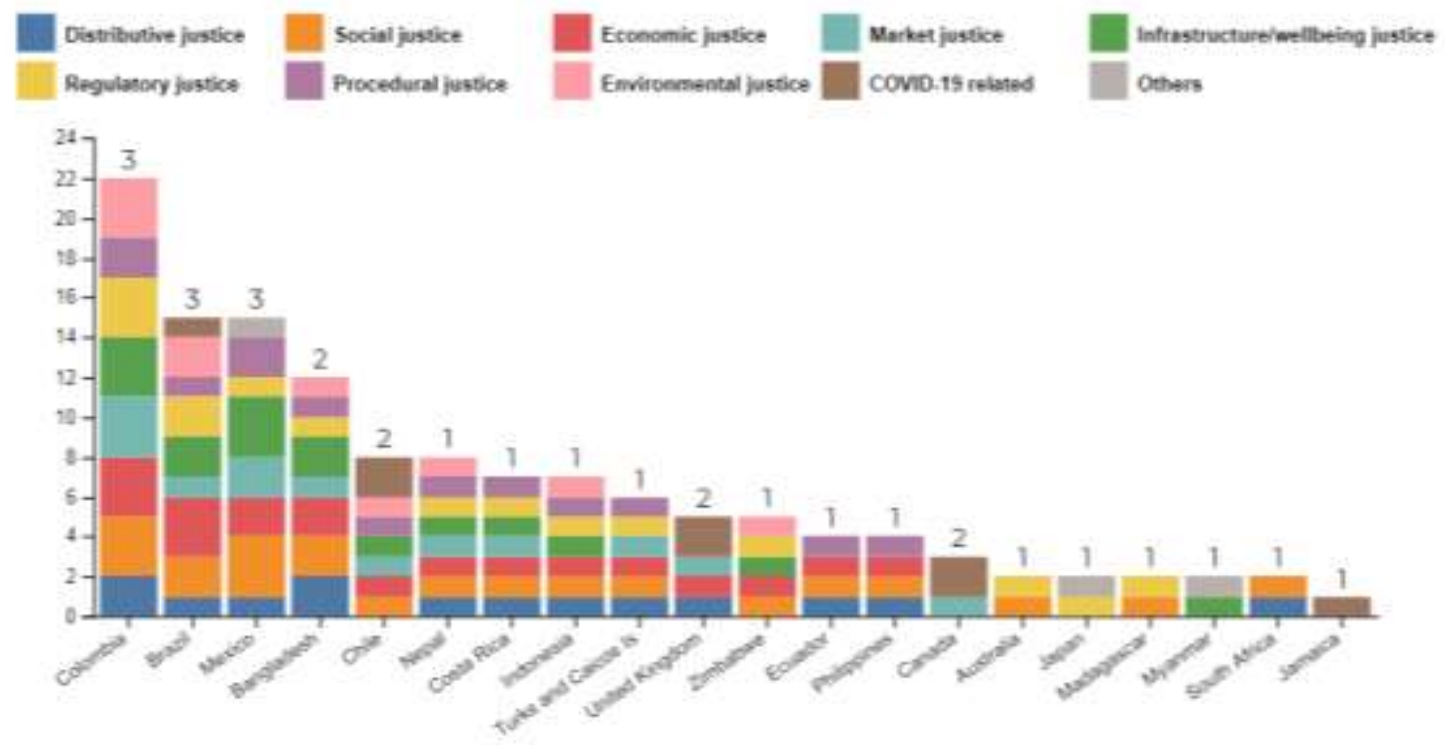

Fonte: https://issfcloud.toobigtoignore.net/.

Adicionalmente, os acontecimentos mais recentes, ligados ao derramamento de óleo na costa brasileira com impactos diretos na pesca (Barboza \& Freitas, 2019), o rompimento de barragens na bacia do rio Doce em Minas Gerais (Noal et al., 2019), ambas em 2019, assim como as restrições impostas pela pandemia do novo coronavírus em 2020 e 2021 (Prysthon, 2020), acrescentaram desafios ainda maiores à crise já em curso da pesca artesanal no Brasil.

Neste contexto, diante de tantas incertezas e demandas socioeconômicas e ambientais prioritárias e urgentes, a Pesquisa, Desenvolvimento e Inovação-PD\&I foi conduzida a ocupar um papel secundário nas demandas dos pescadores artesanais. Como citado anteriormente, mesmo havendo casos de sucesso, o conhecimento ainda permanece fragmentado. Não há dados de monitoramento da atividade (produção, renda, tamanho da frota, número de pescadores, esforço de pesca, espécies capturadas, estados dos estoques pesqueiros, etc.), com exceção de projetos pontuais e isolados, com pouca conexão com políticas públicas.

Com relação ao esforço científico, os grupos de pesquisa em recursos pesqueiros (Pesca e aquicultura), cadastrados na plataforma CNPq, tem registrado em $2021 \mathrm{em}$ sua base corrente, 245 diferentes grupos e 313 linhas de pesquisa. Este esforço está distribuído principalmente nas universidades federais e estaduais, em todas as regiões do país. Destes grupos, apenas dois estão na Embrapa (Amapá e Tocantins).

Considerando a recente missão da Embrapa na temática da pesca artesanal, algumas Unidades Descentralizadas-UD destinam parte do seu esforço para esta área. Porém, somam apenas cinco pesquisadores atuando diretamente com a pesca, a saber: 1 na UD Pesca e Aquicultura (Palmas-TO), 1 na UD Roraima (Boa Vista-RR), 2 a UD Amapá (Macapá-AP) e 1 no Pantanal (Corumbá-MS). Em todas estas UDs, o esforço é voltado para a pesca continental. Portanto, ainda sem UDs atuando em ambientes marinhos/costeiros. A necessidade de atuar na região marinha surge como desafio a ser enfrentado institucionalmente, principalmente por UDs que desempenham missão nacional/regional como a Pesca e Aquicultura (TO), Territórios e Alimentos (AL) e Tabuleiros Costeiros (SE).

Alguns projetos foram conduzidos ao longo dos últimos anos, por exemplo, o PescAraguaia (Conhecimento $e$ adaptação tecnológica para desenvolvimento sustentável da pesca artesanal no rio Araguaia (TO) (SEG MP6 06.14.07.008.00.00) executado entre 2016-2018 e o PROPESCA (Monitoramento e manejo participativo da pesca artesanal 
como instrumento de desenvolvimento sustentável em comunidades da região amazônica (TO/PA/RR) (Fundo Amazônia/BNDES/FEA), ainda em execução (2019 a 2021).

O PescAraguaia gerou importantes conhecimentos sobre comunidades pesqueiras tradicionais na bacia TocantinsAraguaia, assim como na geração de tecnologias de forma participativa, como, por exemplo, o uso de iscas artificiais de baixo custo aumentando a produtividade das redes de emalhe em mais de 50\% (Gentil et al., 2020; Prysthon et al., 2020). No entanto, outras Unidades da Embrapa também já possuem contribuições nesta área como o uso de armadilhas artificiais de material reciclável para aumentar a produtividade de camarões (Lima et al., 2016). Já o Propesca, vem promovendo o monitoramento participativo de desembarques pesqueiros. O Propesca vem gerando mais do que simplesmente informação contínua sobre a pesca. Mas principalmente, a possibilidade de criar e fortalecer um ciclo virtuoso de autoconhecimento dos pescadores sobre e importância da pesca artesanal na produção de alimentos de origem animal, geração de trabalho e renda, e na prestação de serviços ambientais e na segurança alimentar. Ao mesmo tempo que gestores públicos em diferentes esferas (locais, regionais, estaduais, etc.) estão sendo provocados a estabelecerem uma agenda positiva para esta cadeia produtiva em seus municípios/região, sendo a principal delas a criação e manutenção de um programa de monitoramento participativo da pesca como política permanente de geração de dados.

Outras iniciativas na temática da pesca já eram conduzidas anteriormente e hoje estão consolidadas como o sistema de controle e monitoramento da pesca de Mato Grosso (Catella et al., 2017) e os estudos de impactos de barragens na ictiofauna e pesca da bacia pantanal e alto Paraguai, conduzido pela Embrapa pantanal (ANA, 2020). Neste estudo no pantanal, estimou-se que a renda indireta da pesca difusa, ou seja, pescadores eventuais entre 14 e 80 anos, foi de cerca de 1,5 bilhões de reais (ANA, 2020), mostrando a importância indireta da pesca para a socioeconomia desta bacia hidrográfica.

Com relação à pesquisa online, os 74 stakeholders representaram 70 instituições diferentes de diversos segmentos da pesca artesanal marinha e continental (Tabela 2).

Tabela 2. Quantitativo (\%) de representações da pesca artesanal respondentes.

\begin{tabular}{|c|c|}
\hline Tipo de instituição & Participação na pesquisa $(\%)$ \\
\hline Universidades, Institutos Federais e Institutos de Pesquisa & 51,4 \\
\hline Organizações da Sociedade Civil e empresas privadas & 32,9 \\
\hline Órgãos Federais e Secretarias Estaduais & 8,6 \\
\hline Unidades da Embrapa & 7,1 \\
\hline TOTAL & 100 \\
\hline
\end{tabular}

Fonte: Autor.

Os resultados (em \%) da visão de futuro da pesca artesanal (Sinais, Tendencias ou nenhuma delas), baseadas nas demandas do Prospesque-2012, na ordem de prioridade, apontam para uma divisão de opiniões, com divergências importantes para o setor (Tabela 3). Porém, ainda clamam para uma maior atenção governamental, principalmente considerando o atual cenário político-institucional. 
Tabela 3. Panorama da visão de futuro do setor, considerando os respondentes da pesquisa on line.

\section{Demanda da Pesca Artesanal}

Percepção de futuro do setor $(\%)$

\begin{tabular}{|c|c|c|c|}
\hline Demanda da Pesca Artesanal & Sinal & Tendência & $\begin{array}{c}\text { Nenhuma } \\
\text { delas }\end{array}$ \\
\hline $\begin{array}{l}\text { Geração contínua de dados estatísticos da pesca como subsídio para } \\
\text { políticas públicas e implementação de um plano nacional de } \\
\text { monitoramento pesqueiro. }\end{array}$ & 36,5 & 20 & 43,2 \\
\hline $\begin{array}{l}\text { Estudos e pesquisas integradas, bem como estudos sociais, biológicos, } \\
\text { econômicos, ambientais e tecnológicos vinculados à atividade } \\
\text { pesqueira. }\end{array}$ & 47,3 & 32,4 & 20,3 \\
\hline $\begin{array}{l}\text { Dados científicos para embasar as medidas de ordenamento para a } \\
\text { pesca artesanal brasileira. }\end{array}$ & 47,3 & 27 & 25,7 \\
\hline $\begin{array}{l}\text { Estudos de avaliação de impactos sobre a pesca artesanal e os recursos } \\
\text { pesqueiros oriundos de empreendimentos (exemplos: Usinas } \\
\text { hidrelétricas, portos, petróleo e gás, ocupação urbana, etc.). }\end{array}$ & 32,4 & 47,3 & 20,3 \\
\hline $\begin{array}{l}\text { Estudos com enfoque ecossistêmico para subsidiar a gestão de áreas de } \\
\text { pesca e/ou exclusão. }\end{array}$ & 48,6 & 28,4 & 23 \\
\hline $\begin{array}{l}\text { Políticas públicas de estímulo à pesca e/ou comercialização do pescado } \\
\text { à sustentabilidade dos estoques. }\end{array}$ & 40,5 & 13,5 & 45,9 \\
\hline $\begin{array}{l}\text { Capacitação na manipulação do pescado na captura, comercialização e } \\
\text { beneficiamento. }\end{array}$ & 36,5 & 27 & 36,5 \\
\hline $\begin{array}{l}\text { Conhecimentos sobre a biologia das espécies, distribuição geográfica, } \\
\text { ecologia e dinâmica populacional dos recursos pesqueiros. }\end{array}$ & 28,4 & 47,3 & 24,3 \\
\hline $\begin{array}{l}\text { Identificação, prevenção e desenvolvimento estratégias de solução de } \\
\text { conflitos que envolvam múltiplos usuários dos recursos pesqueiros e } \\
\text { ecossistemas aquáticos. }\end{array}$ & 39,2 & 28,4 & 32,4 \\
\hline $\begin{array}{l}\text { Valorização do conhecimento tradicional, dos territórios da pesca e da } \\
\text { segurança alimentar através do peixe. }\end{array}$ & 33,8 & 40,5 & 25,7 \\
\hline $\begin{array}{l}\text { Propostas mais participativas de Gestão da Pesca, promovendo maior } \\
\text { inclusão socioeconômica (exemplo: Acordos de Pesca, Reserva } \\
\text { Extrativista, etc.). }\end{array}$ & 44,6 & 39,2 & 16,2 \\
\hline
\end{tabular}

Fonte: Autor.

Ainda, algumas novas tendencias/sinais foram indicadas pelos respondentes na pesquisa online. Elas foram agrupadas conforme a similaridade e podem ter interação direta ou indireta com as demandas acima, a saber:

Maior ativismo e organização das comunidades de pesca exigindo seus direitos;

Melhor uso dos recursos pesqueiros, principalmente das espécies marinhas que são descartadas;

Estudos voltados para a implantação de Unidades de Beneficiamento de e agregação de valor do pescado e aproveitamento de espécies subutilizada e descartadas; 
$\checkmark \quad$ Aumento da pesca ilegal em Unidades de Conservação Federal/Estadual pela falta de fiscalização, incorporando novos petrechos de pesca com maior esforço de captura;

$\checkmark \quad$ Descontentamento da base pesqueira com as atuais ações do Governo Federal dentre elas: o desmonte sistemático da participação da sociedade civil em fóruns importantes (OEMAs, CONAMA, etc.) e o enfraquecimento de instituições ambientas (ICMBio, IB AMA, etc.) correlatas à pesca artesanal;

$\checkmark \quad$ Plataforma digital de coleta de informações sobre valor de venda do pescado pelo produtor primário artesanal;
$\checkmark \quad$ Criação de polos de aquicultura em comunidades pesqueiras (também no Maranhão);
$\checkmark \quad$ Ausência de assistência técnica;
$\checkmark \quad$ Distanciamento das políticas de cobertura de direitos trabalhistas aos pescadores artesanais;
$\checkmark \quad$ Distanciamento do Plano Nacional De Desenvolvimento Da Pesca E Da Aquicultura;
$\checkmark \quad$ Ordenamento pesqueiro restritivo e sem considerar a participação popular nas tomadas de decisão;
$\checkmark \quad$ Pouca conexão de pesquisa entre Universidades;
$\checkmark \quad$ Maior qualificação técnica de organizações da sociedade civil em fóruns temáticos da pesca.

Considerando os Sinais e Tendencias acima, traçamos alguns possíveis impactos:

A geração contínua de dados (estatística pesqueira) é o principal gargalo, pois sem informação não há gestão. Fornecer dados de forma confiável e contínua é fundamental para subsidiar políticas públicas como a pesquisa, por exemplo. Portanto, um Plano Nacional de monitoramento pesqueiro deve considerar os ambientes marinho e continentais numa única base de dados. Ainda não há sinalização do Governo Federal sobre esta questão.

Estudos integrado, a exemplo do Enfoque ecossistêmico, que consideram variáveis socioeconômicas, ambientais e de governança, precisam ser mais fomentados no Brasil. Projetos como o REBYC II-LAC exemplificam esta demanda, porém ainda são incipientes no Brasil. No entanto, sendo observado como Sinal indica que os impactos deste tipo de estudo provocariam mudanças estruturais na cadeia produtiva, uma vez que consideram os elementos necessários para a gestão pesqueira.

Os dados científicos para embasar medidas de ordenamento levam em consideração pesquisas biológicas pretéritas, porém necessitam ser atualizadas e ajustadas a um contexto mais ecossistêmico. O impacto de novos dados científicos para subsidiar o ordenamento pesqueiro seria positivo, porém devem considerar uma maior participação dos usuários (pescadores) nas tomadas de decisão;

Com relação aos estudos de avaliação de impactos, ainda são poucos os estudos que consideram um olhar mais regional ou por Bacia hidrográfica, porém de alto alcance de divulgação, pois este tipo de estudo tende a ter uma maior repercussão nacional porque conseguem prever impactos que podem ou já ocorreram nos ecossistemas, a exemplo das hidrelétricas (Brasil, 2020), rompimentos de barragens (Noal et al., 2019) e derramamento de petróleo (Barboza \& Freitas, 2019). Estudos desta natureza devem ser conduzidos e provocam um grande impacto positivo para a pesca artesanal, pois colocam em evidência o setor e sua importância socioeconômica e cultural.

Considerando as frágeis Políticas públicas de estímulo à pesca e/ou comercialização do pescado à sustentabilidade dos estoques, observada como uma realidade ainda distante, deixa evidente o impacto negativo desta ausência, principalmente nas organizações da sociedade civil e associações de pescadores (Colônias e Federações de Pesca).

As Capacitação na manipulação do pescado na captura, comercialização e beneficiamento, vista pela maioria como Sinal, é uma questão que pode surtir um impacto positivo a médio-longo prazo. Muitas instituições oferecem capacitações 
(inclusive à distância), principalmente ligadas à extensão rural (ATERs), Universidades e Institutos Federais, Embrapa, etc. Porém, as capacitações de forma geral, oferecem conteúdos "prontos", não considerando a realidade local. Poucas são as iniciativas que compartilham a ideia de capacitação, considerando o conhecimento tradicional e a realidade local.

Sobre o conhecimento da biologia das espécies, o Brasil possui a maior diversidade de peixes do mundo e a biologia das espécies afetadas pela pesca estão relativamente bem descritas, tanto marinho (Frota et al., 2004) quanto continental (Pelicice et al., 2017). O impacto deste conhecimento é positivo uma vez que subsidia o ordenamento pesqueiro e proporciona maior conexão com melhores plano de gestão.

A demanda "identificação, prevenção e desenvolvimento estratégias de solução de conflitos que envolvam múltiplos usuários dos recursos pesqueiros e ecossistemas aquáticos", foi classificada como Sinal. Tal fato pode indicar um impacto positivo uma vez que o mapeamento de projetos que identificam injustiças na pesca (TBTI) é um grande avanço nas ciências pesqueiras, pois as estratégias de resolução de conflitos passam necessariamente por estudos de governança.

Por fim, a valorização do conhecimento tradicional e o estímulo a propostas mais participativas de gestão da pesca, foram avaliadas como tendencia e sinais, respectivamente. Esta percepção tem um impacto positivo, considerando que os recentes acontecimentos negativos ligados ao distanciamento institucional e gradativo deste setor produtivo. Por outro lado, propostas mais inclusivas estão diretamente ligadas à valorização do conhecimento tradicional e o aumento da participação em fóruns e comitês de gestão.

As sugestões de novas demandas relatadas pelos respondentes sugerem maior atenção governamental ao setor diante de um cenário de descontentamento generalizado devido à gradativa redução da participação da sociedade civil em fóruns governamentais. Por outro lado, a indicação de resistência da base pesqueira tem provocado maior ativismo no sentido de reivindicar melhores políticas públicas para o setor da pesca artesanal. Movimentos populares de pescadores são fundamentais para articular e fortalecer demandas legítimas e melhores políticas públicas para a pesca artesanal (Galdino, 2010; Lima \& Callou, 2015).

Por fim, considerando a atuação da Embrapa na pesca artesanal, os recursos humanos necessários para se cumprir uma missão nacional ainda são insuficientes. Porém, é importante fortalecer as redes colaborativas já existentes, agregando competências de outras Unidades Descentralizadas e / ou utilizando o conceito de Unidades-Hub, assim como articulando parcerias com instituições públicas e privadas, sejam locais ou regionais. As Unidades-Hub existem dentro da Embrapa, quando um centro de pesquisa recebe profissionais e apoia a implantação de trabalhos oriundos de outras unidades da Empresa, formando Núcleos Regionais. Quando há uma parceria entre Unidades Descentralizadas, sendo que uma é responsável por um tema ou produto e a outra responsável pela atuação em uma região estratégica, com o objetivo de fortalecer a atuação da Embrapa junto às cadeias produtivas. Portanto, uma UD que recebe profissionais de outra UD passa a ser uma Unidade-Hub.

\section{Conclusão}

Pelo exposto anteriormente e, de acordo com a necessidade complexa e multidisciplinar que a pesquisa pesqueira exige nos diferentes territórios e ambientes, os caminhos institucionais possíveis de PD\&I, para a Embrapa podem considerar:

$\checkmark$ Fomentar, iniciar e/ou apoiar iniciativas que considerem ao Enfoque Ecossistêmico como metodologia, preferencialmente em regiões onde se faz presente estudos sobre o status dos estoques pesqueiros e onde há mecanismos de gestão que favoreçam o aumento na governança dos usuários, a exemplo da região nordeste, sudeste e sul do Brasil;

$\checkmark$ Atuar em ambientes marinhos/costeiros, uma vez que todo o esforço atual está alocado em ambientes continentais. É necessário iniciar um diálogo com a pesca marinha e com públicos mais urbanos, contribuindo para ampliar/fortalecer a imagem corporativa da Embrapa nestes segmentos da sociedade; 
Agregar, realocar ou posicionar competências de outras Unidades Descentralizadas e/ou utilizando o conceito/modelo de Unidades-Hub, com gestão e planos de trabalho compartilhados.

\section{Agradecimentos}

Agradecimento ao Projeto Integrado Fundo Amazônia/BNDES/FEA/Embrapa.

\section{Referências}

Barboza, T. R., \& Freitas, R. R. (2019). Uma análise bibliométrica dos impactos dos derramamentos de óleo na pesca marítima. Pesquisa, Sociedade e Desenvolvimento, $8(1)$, e2281520.

Ministério da Agricultura, informe. Projeto Manejo Sustentável da Fauna Acompanhante na Pesca de Arrasto na América Latina e Caribe - REBYC II-LAC.

Agencia Nacional de Águas-ANA (2020). Elaboração de Estudos de Avaliação dos Efeitos da Implantação de Empreendimentos Hidrelétricos na Região Hidrográfica do Rio Paraguai. Relatório de Andamento 06: Diagnóstico de Ictiofauna, Ictioplâncton e Pesca na RH Paraguai.

Bruna, B., \& Eyng, V. (2020). Universidade memorial. Mobilização da comunidade pesqueira no brasil em meio a desafios multifacetados.

Cattaneo, F. R. A., Souza, L. A., \& Nobrega, K. C. (2017). Um estudo bibliométrico da estratégia do oceano azul. Revista brasileira de administração científica, 8(1), 204-220.

Catella, A. C., Moraes, A. S., Marques, D. K. S., Nascimento, F. L., Lara, J. A. F., Oliveira, M. D., \& Borghesi, R. (2012) Pesca: uma atividade estratégica para a conservação do Pantanal: Embrapa Pantanal, p.

Catella, A. C., Campos, F. L. de R., \& Albuquerque, S. P. (2017). Sistema de Controle de Pesca de Mato Grosso do Sul SCPESCA/MS 23-2016. [recurso eletrônico] / - Dados eletrônicos. - Corumbá: Pantanal; Campo Grande, MS: SEMAGRO: IMASUL, 61 p.

Chuenpagdee, R., \& Jentoft, S. (2019). Transdisciplinarity for Small-Scale Fisheries Governance.

Cochrane, K. L. (2005). Guía Del Administrador Pesquero: Medidas de Ordenación y Su Aplicación: FAO Documento Técnico de Pesca 424.

Diegues, A. C. S. (1983). Pescadores, Camponeses e Trabalhadores do Mar. Ed. Ática. 30p.

FAO. (2020). The State of World Fisheries and Aquaculture 2020. Sustainability in action. Rome.

FAO. (2015). Voluntary Guidelines for Securing Sustainable Small-Scale Fisheries in the Context of Food Security and Poverty Eradication. FAO, Rome, 34.

FAO. (2015). Enfoque Ecosistémico Pesquero. Conceptos Fundamentales y Su Aplicación En Pesquerías de Pequeña Escala de América Latina. edited by O. Defeo. Roma, Italia: FAO Documento Técnico de Pesca y Acuicultura. No. 592.

FAO. (1995). Code of Conduct for Responsible Fisheries Rome, FAO. 1995. 41 p.

Frota, L. O. E., Costa, P. A. S., \& Braga, A. C. (2004). Relações comprimento-peso de peixes marinhos da costa central brasileira. Naga, Worldfish Center Quarterly, 27 (1-2), 20-26.

Galdino, J. W. (2010). Educação e movimentos sociais na pesca artesanal: caso da Prainha do Canto Verde, no litoral cearense. $316 \mathrm{f}$. Tese (Doutorado em Educação) - Universidade Federal do Ceará, Faculdade de Educação, Programa de Pós-Graduação em Educação Brasileira, Fortaleza-CE.

Gentil. E., Prysthon, A., Dias, C. R. G., Silva, F. B., \& Filho M. X. P. (2020). Artificial attractors in small scale fisheries gillnets on Araguaia river, Brazil. Research, Society and Development, 9(8), e913986364.

Graham, J., Amos, B., \& Plumptre, T. (2003). Governance Principles for Protec ted Areas in the 21st Century.

Hilborn, R. (2007). “Managing Fisheries Is Managing People: What Has Been Learned?” Fish and Fisheries 8:285-96.

Kim, C., \& Mauborgne, R. (2005) A estratégia do oceano azul: como criar novos mercados e tornar a concorrência irrelevante: Campus-Elsevier.

Lima, J. de F., Bastos, A. M., \& Montagner, D. (2016). Armadilha em PVC para a pesca comercial de camarões de água doce: Embrapa Amapá, 5. (Embrapa Amapá. Comunicado técnico, 143).

Lima, A. C., \& Callou, A. B. (2015). Políticas públicas e assistência técnica para pesca artesanal em Pernambuco. Revista Contexto \& Educação, 30(95), 93116.

Lima, et al., (2012). Relatório técnico do Seminário Nacional de Prospecção de Demandas da Cadeia Produtiva da Pesca: PROSPESQUE / Adriana Lima. [et al.]: Embrapa, 2012. 88 p.

Lynch A. J., Cooke, S. J., Deines, A. M., Bower, S. D., Bunnel, D. B., Cowx, I. G., Nguyen, V. M., Nohner, J., Phouthavong, K., Riley, B., Rogers, M. W., Taylor, W. W., Woelmer, W., Youn, S. J., \& Douglas, Jr. B.T (2016). The social, economic, and environmental importance of inland fish and fisheries. Environmental Reviews. 24(2): 115-121.

Lopes, I. G., Oliveira, R. G., \& Ramos, F. M. (2016). Perfil do consumo de peixes pela população brasileira. Biota Amazônia, 6(2), 62-65. 
Research, Society and Development, v. 10, n. 3, e45010313572, 2021

(CC BY 4.0) | ISSN 2525-3409 | DOI: http://dx.doi.org/10.33448/rsd-v10i3.13572

Lowe-Mcconnell, R. H. (1999). Estudos Ecológicos de Comunidades de Peixes Tropicais. Edusp, 535 p.

MPA (2013). Boletim do registro geral da atividade pesqueira -RGP 2012. http://www.mpa.gov.br/images/Docs/Pesca/Boletim\%20do\%20 Registro\%20Geral\%20da\%20Atividade\%20Pesqueira\%20-\%202012\%281\%29.

Noal, D. S., Rabelo, I. V. M. \& Chachamovich, E. (2019). O impacto na saúde mental dos afetados após o rompimento da barragem da Vale. Cadernos de Saúde Pública. 35(5).

Oviedo, A. F. P. (2017). Pescadores de Manoel Urbano e a construção de um território de pesca numa perspectiva etnoecológica. Revista Ciências da Sociedade (RCS), 1(2), 103-126, Jul/Dez.

Pauly, D., \& Zeller, D. (2016). Catch reconstructions reveal that global marine fisheries catches are higher than reported and declining. Nat Commun 7, 10244.

Pelicice, F. M., Azevedo-Santos, V. M., Vitule, J. R. S., Orsi, M. L., Lima-Junior, D. P., Magalhães, A. M. B., Pompeu, P. S., Petrere-Jr, M., \& Agostinho, A. A. (2017). Neotropical freshwater fishes imperilled by unsustainable policies. Fish and Fisheries. 18: 1119- 1133.

Pereira, A. S., et al. (2018). Metodologia da pesquisa científica. UFSM.

Prysthon, A. (2020). Percepção do impacto da pandemia do Covid-19 nas comunidades pesqueiras monitoradas pelo PROPESCA no Tocantins e no Pará: Embrapa Pesca e Aquicultura, 2020. 3 p. (Propesca informa, 10).

Prysthon, A., Gentil, E., Pedroza Filho, M. X., \& Araujo, C. (2020). Iscas artificiais de baixo custo para as redes de emalhe da pesca artesanal, rio Araguaia,Tocantins: Embrapa Pesca e Aquicultura, 8 p. (Embrapa Pesca e Aquicultura. Comunicado técnico, 3).

Salas, S., Barragan-paladines, M. J. \& Chuenpagdee, R. (Eds.), (2019). Viability and Sustainability of Small-Scale Fisheries in Latin America and The Caribbean.

Silva, A. P. da. (2014). Pesca artesanal brasileira. Aspectos conceituais, históricos, institucionais e prospectivos/ Adriano Prysthon da Silva - Palmas: Embrapa Pesca e Aquicultura.

Zamboni, A. (2020). Auditoria da pesca: Brasil 2020 [livro eletrônico]: uma avaliação integrada da governança, da situação dos estoques e das pescarias I Ademilson. Zamboni, Martin Dias, Lara Iwanicki. Oceana Brasil. 